This suggests that the public may be prepared to choose to have less spent on one service to have the benefits of another.

Out results have given a general impression of the public's views. The survey raised awareness in the health authority of the need to open a dialogue with residents. Purchasers will wish to find ways in which they can identify and react to public opinions. As well as providing a means of doing this, surveys can contribute to public awareness and knowledge.

We thank Geoff Griffiths, director of planning and partnership, Bath District Health Authority, for his help with drafting the questionnaire; Mrs Sue Jones for help with data entry; and members of the public who completed the questionnaires.
1 Hicks NR, Baker IA. General practitioners' opinions of health services available to their patients. BMF 1991;302:991-3.

Fitzpatrick R. Survey's of patient satisfaction. II. Designing a questionnaire and conducting a survey. BMf 1991;302:1129-32.

$3 \mathrm{Yu} \mathrm{J}$, Cooper $\mathrm{H}$. A quantitative review of research design effects on response rates to questionnaires. Joumal of Marketing Research 1983;XX (February): $36-44$

4 Mortagy AK, Howell JBL, Waters WE. A useless raffle If Epidemiol Community Health 1985;39:183-4.

5 Statistical package for the social sciences, SPSS PC+[computer program]. Chicago, Illinois: SPSS, 1988 .

6 Williams A. Economics of coronary artery bypass grafting. BMF 1985;291: $326-9$

7 Dixon J, Welch HG. Priority setting: lessons from Oregon. Lancet 1991;337 $891-4$.

8 Donabedian A. The quality of care-how can it be assessed? FAMA 1988;260 $17+3-8$

9 Department of Health. The NHS reforms and you. London: HMSO, 1990

(Accepted 20 December 1991)
Public Health Laboratory Disease Surveillance Centre, Colindale, London NW9 5EQ

Joanne $M$ White, BSC, principal scientist

Norman T Begg, MFPHM, consultant epidemiologist Conor P Farrington, PHD, principal statistician

North West Thames

Regional Health Authority, London W2 3QR

Stephen J Gillam, MRCP, senior registrar in public health medicine

Correspondence to: $\mathrm{Ms}$ White.

\title{
Vaccine coverage: recent trends and future prospects
}

\author{
Joanne M White, Stephen J Gillam, Norman T Begg, Conor P Farrington
}

\section{Abstract}

Objective-To assess the feasibility of achieving the target of $95 \%$ coverage for the childhood immunisation schedule by 1995 and to determine the influence of sociodemographic factors and information systems on recent trends.

Design-Analyses of trends in quarterly vaccination data for diphtheria, pertussis, and measles in health districts between February 1988 and February 1991.

Setting-District health authorities in England and Wales, and health and social services boards in Northern Ireland.

Subjects-Cohorts of children whose youngest member had reached the target age of 18 months for receiving the third doses of diphtheria and pertussis vaccines and 2 years for receiving measles vaccine.

Results-Predicted coverage levels for mid-1995 were in excess of $95 \%$ for diphtheria, pertussis, and measles vaccines. In the 118 districts that continuously reported between February 1988 and February 1991 the increase in coverage was 6\% for diphtheria and $13 \%$ for pertussis and measles vaccines. 1991 coverage depended primarily on 1988 coverage. The additional effects of deprivation, change in computer system, and child population size achieved at most only marginal statistical significance.

Conclusions-The government's target of $95 \%$ coverage by 1995 is realistic, although projections should be viewed with caution. Several national vaccination initiatives are likely to have contributed to the recent steady increase in coverage. Updating and validation exercises are likely to improve recorded coverage.

\section{Introduction}

Substantial improvements in coverage of childhood vaccinations have been reported over the past 10 years. Statistics from the Department of Health (unpublished) show that between 1979 and 1989-90 coverage in England rose from $80 \%$ to $89 \%$ for diphtheria, tetanus, and polio; from $51 \%$ to $84 \%$ for measles; and from $35 \%$ to $78 \%$ for pertussis. This achievement has been brought about by a combination of organisational change, health education, and professional commitment to the programme.' What further improvements in vaccine coverage might we expect? The government's recent proposals for a national health strategy include a target of $95 \%$ coverage for the childhood immunisation schedule by 1995.' This will be achieved only if continuing improvements can be shown in all districts, including those with characteristics beyond the control of the health service such as high population mobility and unemployment. ${ }^{3}$ None of this will be possible without accurate, timely information. The efficiency of child health computer systems is therefore of paramount importance.

The most recent Department of Health statistics relate to children who reached their second birthday between April 1989 and March 1990. However, more up to date information on vaccine coverage is available from the COVER (cover of vaccination evaluated rapidly) scheme,${ }^{4}$ which was established by the Public

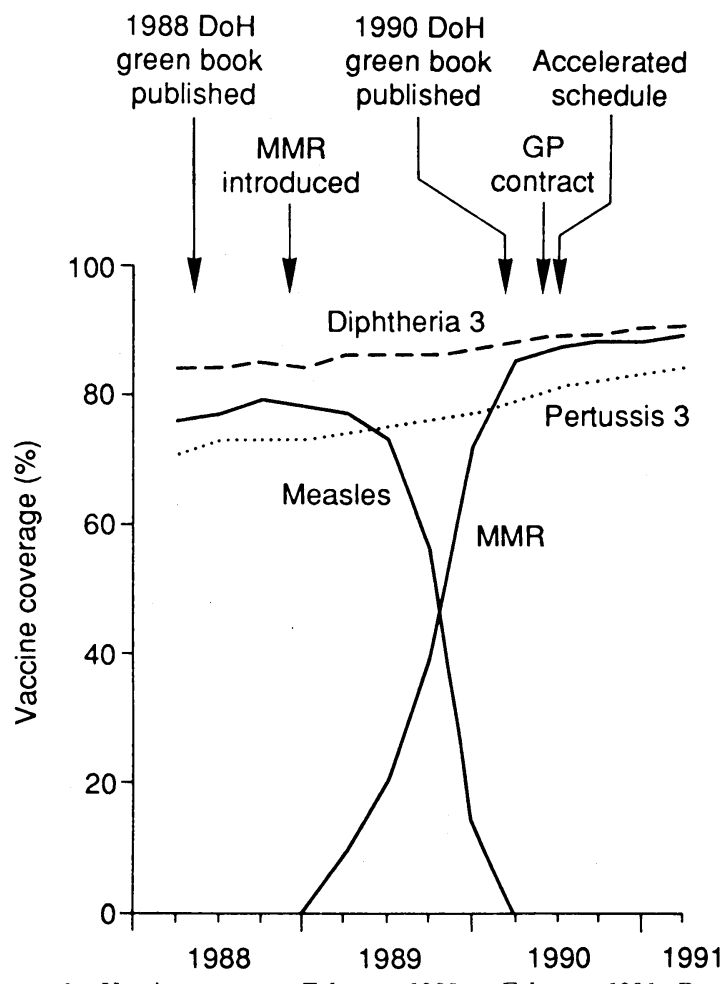

FIG 1-Vaccine coverage, February 1988 to February 1991. Percentage coverage of third dose diphtheria and pertussis, single antigen measles, and measles, mumps, and rubella (MMR) vaccines (all reporting districts). (Source: COVER (cover of vaccination evaluated rapidly) scheme 

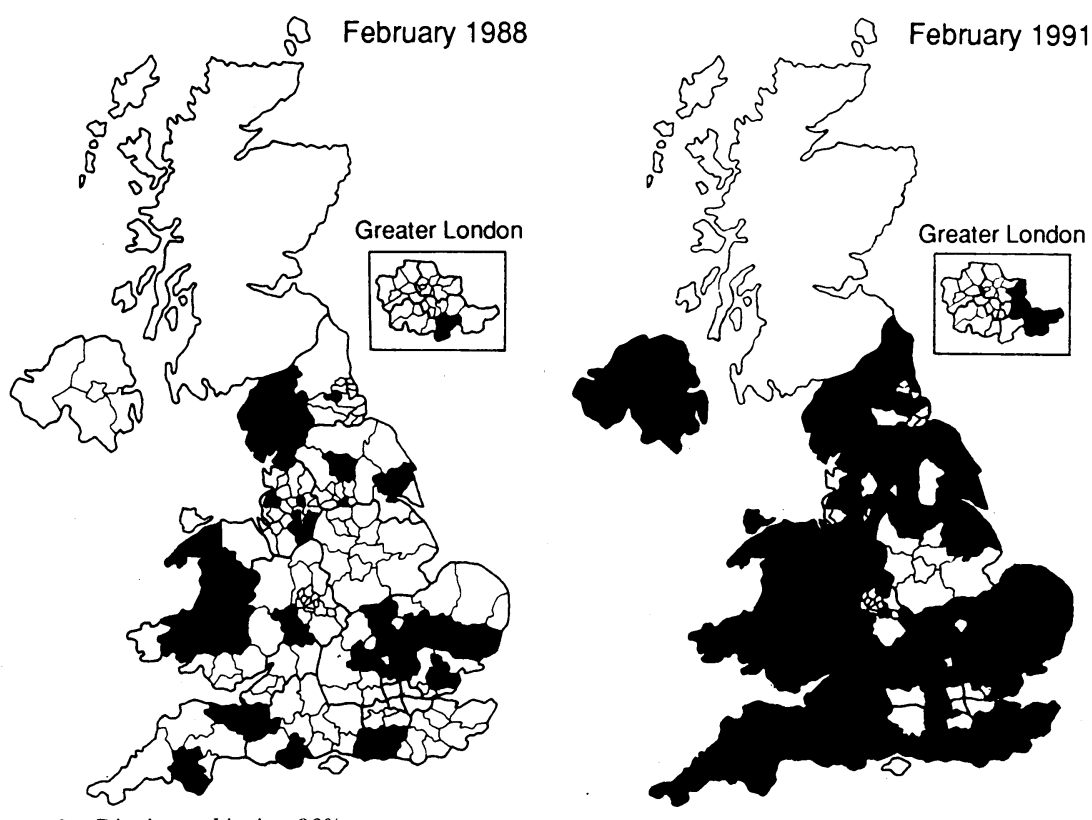
coverage for third dose diphtheria, England, Wales, and Northern Ireland

Health Laboratory Service Communicable Disease
FIG 2-Districts achieving $90 \%$ Surveillance Centre in 1987 . Over $95 \%$ of districts in England, Wales, and Northern Ireland currently contribute to the COVER scheme, and the data are now routinely used by the department in assessing national performance. The aim of this study was to assess the feasibility of achieving the $95 \%$ target by analysing recent trends in COVER data and the influence of sociodemographic factors and information systems on these trends.

\section{Subjects and methods}

Quarterly vaccination data for diphtheria, pertussis, and measles were requested from health districts in England and Wales (from February 1987) and Northern Ireland (from August 1989). Cohorts of children studied were those whose youngest member had reached the target age for receiving the three sentinel vaccines: 18 months for diphtheria (third dose) and pertussis (third dose) and 2 years for measles. For districts using the NHS child health system, data were available as routine output from the computer. ${ }^{5}$ In the other districts ad hoc programmes were written to provide the data.

Analyses of trends were carried out for the period February 1988 to February 1991. During this time the number of districts providing data increased from 122 to 193, of which 118 reported every quarter. Two types of analyses were performed by using different data sets: (1) projections of vaccine coverage to 1995 were derived from analyses of trends in all reporting districts; (2) associations between sociodemographic variables, information systems, and 1991 vaccine coverage were sought by using the subset of 118 districts that reported to every quarterly evaluation between 1988 and 1991 .

\section{PROJECTIONS OF VACCINE COVERAGE}

For some districts it was not possible to obtain accurate figures for total measles coverage for evaluation immediately after the introduction of measles, mumps, and rubella vaccine. These records were therefore excluded. The total number of quarterly district evaluations analysed was 2096 for diphtheria and pertussis and 1601 for measles. Trends were modelled by logistic quadratic regression ${ }^{6}$ of the number of children vaccinated in each reporting district against time. By using these regression equations projections were obtained for mid-1995 along with $95 \%$ prediction limits.
VARIABLES ASSOCIATED WITH I99I COVERAGE

Districts were classified according to social deprivation, size of the 1991 child population, and whether or not they had changed their computer system since February 1988. Social deprivation was measured by the underprivileged area score, ${ }^{7}$ which for the 118 districts considered ranged from -26.64 (least deprived) to 54.66 (most deprived). For descriptive purposes districts with a score below 0 were classified as low deprivation and those with a score of 0 or greater as high deprivation. Districts were also classified as small or large according to whether the number of children in the cohort evaluated in February 1991 fell below or above the mean for all participating districts.

The relations between these variables and the $1991 \frac{5}{2}$ coverage after allowing for different 1988 baselines $\stackrel{\curvearrowright}{\Omega}$ were investigated by logistic regression ${ }^{6}$ of the numbers $\nRightarrow$ of children vaccinated in each of the 118 districts in $\vec{A}$ February 1991. The following covariates were used: logit of percentage coverage in February 1988, under- $\vec{\omega}$ privileged area score, change in computer system, and $O$ size of childhood population in February 1991. The analysis used the logits of coverage proportions rather than the proportions themselves. Consequently results are reported in terms of coverage odds (proportion vaccinated/proportion unvaccinated), and parameter estimates are expressed as odds ratios.

In both regression analyses the considerable extrabinomial variability attributable to variations between $ᄋ$ districts and birth cohorts was modelled by using the quasilikelihood method of Williams. ${ }^{8}$

\section{Results}

There was a steady increase in coverage for all three $\bar{\emptyset}$ sentinel antigens between February 1988 and February ? 1991 (fig 1). During this period the percentage of reporting districts that achieved $90 \%$ coverage rose from $29 \%(35 / 122)$ to $70 \%(135 / 193)$ for diphtheria (fig 2), from $0 \%(0 / 122)$ to $19 \%(36 / 193)$ for pertussis, ํำ and from $2 \%(3 / 122)$ to $63 \%(121 / 193)$ for measles.

In the 118 districts that reported in every quarter between February 1988 and February 1991 the increase $\frac{\circ}{3}$ in coverage was $6 \%$ for diphtheria and $13 \%$ for pertussis and measles (table I). The predicted levels of coverage in mid-1995, obtained by extrapolating the 1988-91 trends, were $99 \%$ for diphtheria and pertussis and $97 \%$ for measles. The lower limits of the $95 \%$ prediction intervals were $97 \%$ (diphtheria), $98 \% \frac{5}{3}$ (pertussis), and $91 \%$ (measles).

\section{VARIABLES ASSOCIATED WITH 1991 COVERAGE}

Table II shows the coverage figures for 1988 and 윽 1991 by dichotomised deprivation score, childhood o population, and change in computer system. Coverage increased between the two evaluations for each antigen in all strata. The more deprived districts achieved N lower coverage than the less deprived ones for both $N$ time periods, although the difference in percentage coverage was less in 1991 than 1988. Districts with small and large child populations performed similarly.

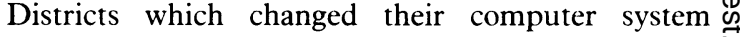
between 1988 and 1991, though starting from lower TABLE II - I'accine coverage in 118 districts: February 1988 and $\frac{\mathrm{O}}{\mathrm{D}}$ February 1991. Figures are percentages February 1991. Figures are percentages

\begin{tabular}{|c|c|c|}
\hline & Coverage & \\
\hline & 19881991 & Increase \\
\hline Diphtheria & 84.490 .8 & $6 \cdot 4$ \\
\hline Pertussis & $71 \cdot 684 \cdot 7$ & $13 \cdot 1$ \\
\hline Measles & $76 \cdot 0 \quad 88 \cdot 8$ & $12 \cdot 8$ \\
\hline
\end{tabular}

\begin{tabular}{|c|c|c|c|c|c|c|c|}
\hline \multirow[b]{2}{*}{ District characteristics } & & \multicolumn{2}{|c|}{ Diphtheria } & \multicolumn{2}{|c|}{ Pertussis } & \multicolumn{2}{|c|}{ Measles } \\
\hline & & 1988 & 1991 & 1988 & 1991 & 1988 & 1991 \\
\hline Deprivation & $\left\{\begin{array}{l}\text { High } \\
\text { Low }\end{array}\right.$ & $\begin{array}{l}78 \cdot 4 \\
87 \cdot 2\end{array}$ & $\begin{array}{l}88 \cdot 4 \\
92 \cdot 1\end{array}$ & $\begin{array}{l}66 \cdot 9 \\
74 \cdot 1\end{array}$ & $\begin{array}{l}82 \cdot 4 \\
86 \cdot 0\end{array}$ & $\begin{array}{l}71 \cdot 3 \\
78 \cdot 7\end{array}$ & $\begin{array}{l}86 \cdot 3 \\
90 \cdot 3\end{array}$ \\
\hline Childhood population & $\left\{\begin{array}{l}\text { Small } \\
\text { Large }\end{array}\right.$ & $\begin{array}{l}84 \cdot 9 \\
84 \cdot 1\end{array}$ & $\begin{array}{l}91 \cdot 1 \\
90 \cdot 7\end{array}$ & $\begin{array}{l}72 \cdot 4 \\
71 \cdot 0\end{array}$ & $\begin{array}{l}85 \cdot 1 \\
84 \cdot 4\end{array}$ & $\begin{array}{l}76 \cdot 9 \\
75 \cdot 5\end{array}$ & $\begin{array}{l}89 \cdot 7 \\
88 \cdot 3\end{array}$ \\
\hline $\begin{array}{l}\text { Change in computer } \\
\text { system }\end{array}$ & $\left\{\begin{array}{l}\text { Yes } \\
\text { No }\end{array}\right.$ & $\begin{array}{l}81 \cdot 4 \\
85 \cdot 4\end{array}$ & $\begin{array}{l}90 \cdot 7 \\
90 \cdot 9\end{array}$ & $\begin{array}{l}70 \cdot 0 \\
72 \cdot 1\end{array}$ & $\begin{array}{l}84 \cdot 9 \\
84 \cdot 7\end{array}$ & $\begin{array}{l}73 \cdot 3 \\
76 \cdot 9\end{array}$ & $\begin{array}{l}88 \cdot 8 \\
88 \cdot 9\end{array}$ \\
\hline
\end{tabular}


1991 Coverage odds ratio ( $95 \%$ confidence interval)

\begin{tabular}{|c|c|c|c|c|}
\hline Variable & Unit of measurement & Diphtheria & Pertussis & Measles \\
\hline $\begin{array}{l}1988 \text { Coverage } \\
\text { Deprivation score }\end{array}$ & $\begin{array}{l}\text { Twofold difference in odds } \\
10 \text { Points on underprivileged } \\
\text { area scale }\end{array}$ & 84) & $\cdot 85)$ & $1 \cdot 61$ \\
\hline $\begin{array}{l}\text { Childhood population } \\
\text { Change in computer }\end{array}$ & $\begin{array}{l}\text { area scale } \\
100 \text { Children }\end{array}$ & $\begin{array}{l}0.97(0.92 \text { to } 1.03) \\
1.00(0.98 \text { to } 1.02)\end{array}$ & $\begin{array}{l}0.98(0.95 \text { to } 1.01) \\
0.99(0.98 \text { to } 1.01)\end{array}$ & $\begin{array}{l}0.94(0.89 \text { to } 1.00) \\
0.99(0.97 \text { to } 1.01)\end{array}$ \\
\hline system & Not applicable & $1.14(0.95$ to 1.37$)$ & $1.07(0.96$ to 1.20$)$ & $1 \cdot 10(0.91$ to 1.32$)$ \\
\hline
\end{tabular}

coverage in 1988 than those which did not, achieved similar coverage in 1991.

As expected, 1991 coverage was strongly correlated with 1988 coverage, a twofold difference in coverage odds in 1988 corresponding to a $1 \cdot 6$-fold difference in 1991 (table III). Greater deprivation was found to correspond with lower coverage odds in 1991 (an increase of 10 points in the underprivileged area score corresponding to odds ratios 0.94 to 0.98 ), though this was significant at the $5 \%$ level only for measles. Changing the computer system corresponded to an appreciably, though not statistically significantly, higher coverage odds (odd ratios 1.07 to $1 \cdot 14$ ). Child population size had no effect.

\section{Discussion}

\section{PROJECTIONS OF VACCINE COVERAGE}

A number of national vaccination initiatives were launched during the study period, including the introduction of measles, mumps, and rubella vaccine; an accelerated immunisation schedule; publication of revised guidelines ${ }^{910}$; and incentives under the new general practitioner contract. All of these are likely to have contributed to the observed improvements in coverage. The steady rate of increase shown in figure 1 suggests that it is not possible from this study to single out any one initiative that exerted a greater effect than others. It has been suggested that the contractua incentives may exert a perverse influence in areas where general practitioners perceive the likelihood of achieving targets to be slight. ${ }^{11}$

Based on trends observed in this study, the predicted coverage levels for 1995 are in excess of $95 \%$. This suggests that the government's $95 \%$ target is realistic, although projections of this nature should be viewed with extreme caution. In particular, the calculations make the improbable assumption that the particular functional form chosen to describe recent changes in coverage will also apply in future. It is also assumed that, in principle, every child may receive vaccine. In reality contraindications will apply to a few. Finally, it is assumed that no events such as adverse publicity will affect the vaccination programme.

\section{VARIABLES ASSOCIATED WITH 1991 COVERAGE}

The 118 districts selected for this analysis represented over half of all districts in the United Kingdom. The coverage rates for these 118 districts were within $2 \%$ of the national average, and every region in England and Wales was represented. The average deprivation score was $-0 \cdot 15$, close to the national average of zero. Thus the conclusions drawn from this sample are not likely to be subject to substantial bias.

Low vaccination coverage has been associated with adverse socioeconomic conditions. ${ }^{312}$ Nevertheless, good coverage can be achieved among disadvantaged populations. ${ }^{13}{ }^{14}$ In this study, though deprived districts had lower overall cover, the biggest improvements occurred in some of the most deprived districts. Professional disorganisation and lack of commitment may be more important determinants than staffing levels and social factors. ${ }^{1}$

Vaccination records in low coverage districts are widely perceived as inaccurate. ${ }^{15}$ Districts in this study that had changed their computer system showed the greatest increases in coverage. It is likely that such a change within a district will focus attention on the quality of data being collected and entered. Updating and validation exercises are likely to improve recorded coverage.

Coverage levels achieved in 1991 depended primarily on 1988 levels. The additional effects of district deprivation, child population size, and change in computer system were found to operate in the directions expected: greater social deprivation as a hindrance; improved computer system as a help; size of child population without effect. However, none of these effects were statistically significant, with the sole exception of district deprivation on measles coverage. This exception may be attributable to measles vaccine being given later; measles, mumps, and rubella vaccine is given at $12-15$ months compared with $8-10$ months for completion of the diphtheria and pertussis courses.

The results of this study suggest that high levels of vaccine coverage are achievable in all districts. Provided the current impetus can be maintained, elimination of vaccine preventable infections in the United Kingdom now seems possible.

1 Nicoll A, Elliman D, Begg NT. Immunisation: causes of failure and strategies and tactics for success. BMF 1989;299:423-4.

2 Health of the nation. A consultative document for health in England. London: HMSO, 1991. (Cm 1523.)

3 Jarman B, Bosanquet N, Rice P, Dollimore N, Leese B. Uptake of immunisation in district health authorities in England. $B M \mathcal{F}^{1988 ; 296}$ $1775-8$

4 Begg NT, Gill ON, White JM. COVER (cover of vaccination evaluated rapidly). Description of the England and Wales scheme. Public Health

5 Child Health Computing Committee. The child health system-a statistical guide. Cardiff: Welsh Health Common Service Authority, 1987

6 Aitkin M, Anderson D, Francis B, Hinde J. Statistical modelling in GLIM. Oxford: Clarendon Press, 1989

7 Jarman BJ. Underprivileged areas: validation and distribution of scores. $B M \mathcal{J}$ 1984;289:1587-92.

8 Williams DA. Extra-bimonial variation in logistic linear models. Applied Statistics 1982;31:144-8.

9 Department of Health. Immunisation against infectious disease. London HMSO, 1988.

10 Department of Health. Immunisation against infectious disease. London: HMSO, 1990.

11 Lawrence M. Targets and the GP contracts. BMF 1989;299:389.

12 Mant D, Phillips A, Knightley M. Measles immunisation rates and the good practice allowance. $B M 7$ 1986;293:955-7.

13 James J, Clark C, Rossdale $M$. Improving health care delivery in an inner-city well-baby clinic. Arch Dis Child 1986;61:251-6.

14 Ross SK. Childhood immunoprophylaxis: achievements in a Glasgow practice. Health Bull 1986;44:370-3.

15 Lakhani A, Morris R, Morgan M, Dale C, Vaile M. Report of an investigation of the low measles immunisation in Maidstone Health Authority. London Department of Community Medicine, St Thomas's Hospital, 1986.

(Accepted 20 December 1991) 